\title{
Effect of Cytochrome P450 2C19 Polymorphism on Target Lesion Outcome After Drug-Eluting Stent Implantation in Japanese Patients Receiving Clopidogrel
}

Ryo Nishio, MD; Toshiro Shinke, MD; Hiromasa Otake, MD; Takahiro Sawada, MD; Yoko Haraguchi, MD; Masakazu Shinohara, MD; Ryuji Toh, MD; Tatsuro Ishida, MD; Masayuki Nakagawa, MD; Ryoji Nagoshi, MD; Amane Kozuki, MD; Takumi Inoue, MD; Hirotoshi Hariki, MD; Tsuyoshi Osue, MD; Yu Taniguchi, MD; Masamichi Iwasaki, MD; Noritoshi Hiranuma, MD; Akihide Konishi, MD; Hiroto Kinutani, MD; Junya Shite, MD; Ken-ichi Hirata, MD

\begin{abstract}
Background: Cytochrome P450 (CYP) 2C19 polymorphism is associated with reduced responsiveness to clopidogrel and poor clinical outcome after drug-eluting stent (DES) implantation, but its contribution to lesion outcome after DES implantation is unclear.
\end{abstract}

\begin{abstract}
Methods and Results: The study included 160 Japanese patients who received clopidogrel and underwent DES implantation with follow-up angiography. Patients were divided into 3 groups by CYP2C19 polymorphism: extensive metabolizers (EM), intermediate metabolizers (IM), and poor metabolizers (PM). The incidence of major adverse cardiac events (MACE) and target lesion revascularization (TLR) were compared among the 3 groups. Optical coherence tomography (OCT) was performed for 120 patients to evaluate the incidence of intra-stent thrombi. Of the 160 patients, the proportion of EM, IM, and PM was $37.5 \%, 48.1 \%$, and $14.4 \%$, respectively. The incidence of TLR and MACE was more frequent in IM and PM than EM (TLR: $18.2 \%$ and $26.1 \%$ vs. $3.3 \%, P=0.008$, MACE: $22.1 \%$ and $30.4 \%$ vs. $5.0 \%, P=0.005)$. Among the 120 patients who underwent follow-up OCT, intra-stent thrombi were more frequently detected in IM and PM than in EM (45.6\% and $63.2 \%$ vs. $20.5 \%, P=0.005)$. The incidence of TLR was significantly higher in patients with than in those without intra-stent thrombi $(27.7 \%$ vs. $6.8 \%, P=0.003)$.
\end{abstract}

Conclusions: CYP2C19 loss-of-function polymorphism might be associated with the incidence of MACE and TLR in association with intra-stent thrombi. (Circ $J$ 2012; 76: 2348-2355)

Key Words: CYP2C19; Intra-stent thrombi; Major adverse cardiac events; Optical coherence tomography; Target lesion revascularization

D ual antiplatelet therapy with aspirin plus a thienopyridine derivative is recommended for the prevention of thrombotic events in patients with coronary artery disease who have undergone drug-eluting stent (DES) implantation. ${ }^{1}$ Clopidogrel, a thienopyridine derivative, is a prodrug that is converted into an active metabolite in the liver and the metabolite irreversibly inhibits the adenosine diphosphate P2Y12 receptor. ${ }^{2}$ Because the conversion is achieved by the hepatic cytochrome P450 (CYP) system in a 2-step oxidative process and CYP2C19 is involved in both of these steps, polymorphisms of the genes encoding CYP2C19 are considered to influence clopidogrel's efficacy by affecting the activity of its metabolite. ${ }^{3-5}$ Among the single nucleotide polymorphisms of CYP2C19, the CYP2C19*2 polymorphism (mutation of guanine to adenine at position 681 in exon 5) and the CYP2C19*3 polymorphism (mutation of guanine to adenosine at position 636 in exon 5) are considered to be important loss-of-function polymorphisms. Previous studies demonstrated that the CYP2C19*2 and CYP2C19*3 polymorphisms increase the risk of stent thrombosis, ${ }^{6-8}$ but only limited data are available regarding the association between the presence of CYP2C19 polymorphisms and future lesion outcomes after DES therapy.

Received April 11, 2012; revised manuscript received May 9, 2012; accepted June 5, 2012; released online July 3, 2012 Time for primary review: 11 days

Department of Internal Medicine, Division of Cardiovascular Medicine, Kobe University Graduate School of Medicine, Kobe, Japan

Mailing address: Toshiro Shinke, MD, Associate Professor, Department of Internal Medicine, Division of Cardiovascular Medicine, Kobe

University Graduate School of Medicine, 7-5-1 Kusunoki-cho, Chuo-ku, Kobe 650-0017, Japan. E-mail: shinke@ med.kobe-u.ac.jp

ISSN-1346-9843 doi:10.1253/circj.CJ-12-0476

All rights are reserved to the Japanese Circulation Society. For permissions, please e-mail: cj@j-circ.or.jp 
We previously suggested that the frequency of subclinical thrombus detected by optical coherence tomography (OCT) is increased in association with the CYP2C19*2 polymorphism. ${ }^{9}$ Based on recent pathologic and clinical studies suggesting a role of thrombus formation in DES restenosis, ${ }^{10,11}$ we hypothesized that the presence of CYP2C19 polymorphisms is associated with lesion outcomes after DES treatment. Therefore, in the present study, we evaluated the effect of CYP2C19 lossof-function polymorphisms on long-term target lesion outcome after DES implantation.

\section{Methods}

\section{Patients}

This study was approved by the ethics committee of Kobe University, and all enrolled study patients provided written informed consent to participate in the clinical trial and genetic study. Between June 2008 and June 2010, 302 patients at Kobe University Hospital underwent percutaneous coronary intervention (PCI) with a DES (sirolimus-eluting stent [SES]: Cypher ${ }^{\mathrm{TM}}$; Cordis Corp, Miami Lakes, FL USA; paclitaxel-eluting stent [PES]: TAXUS Express ${ }^{\mathrm{TM}}$ or TAXUS Liberte ${ }^{\mathrm{TM}}$; Boston Scientific Corporation, Natick, MA, USA). All PCIs were performed with intravascular ultrasound guidance (Boston Scientific Corporation or Volcano Corporation, Rancho Cordova, CA, USA). Follow-up angiography was planned at 8-10 months after the index procedure as routine follow-up practice. Recurrence of chest symptoms and evidence of myocardial ischemia on a stress test were also considered to be indications for repeat angiography. All patients were encouraged to undergo OCT examination at the time of the follow-up angiography. Of the 302 patients, 212 patients underwent follow-up angiography and of these, 160 patients agreed to the CYP2C19 polymorphism analysis and were enrolled in the study.

The patients' characteristics, including age, sex, body mass index, and the presence of coronary risk factors (hypertension, dyslipidemia, diabetes mellitus, and smoking) were assessed. Additional drug usage was also assessed, because the prognosis after PCI and the response to clopidogrel is potentially influenced by concomitant medications, such as proton-pump inhibitors, calcium-channel blockers, statins, $\beta$-blockers, angiotensin-converting enzyme inhibitors, angiotensin-receptor blockers, and warfarin. ${ }^{12,13}$

All patients treated with a DES received dual antiplatelet therapy with aspirin and clopidogrel. The loading dose of clopidogrel $(300 \mathrm{mg}$ ) was administered at least $24 \mathrm{~h}$ before the procedure, followed by a maintenance dose of clopidogrel ( $75 \mathrm{mg} /$ day) and aspirin ( $100 \mathrm{mg} /$ day) until at least 1 year after the procedure. A longer duration of clopidogrel use was permitted at the discretion of the treating physician.

\section{Blood Sampling and Genotyping Methods}

We obtained blood samples from the arterial sheath at the time of follow-up angiography. Genomic DNA was extracted from whole blood using the commercially available QIAamp ${ }^{\mathrm{TM}}$ DNA Blood Mini kit (QIAGEN N.V., Venlo, The Netherlands) according to the manufacturer's instructions. The CYP2C19*2 $(681 \mathrm{G}>\mathrm{A})$ or $* 3(636 \mathrm{G}>\mathrm{A})$ polymorphism was genotyped using TaqMan $^{\text {TM }}$ Drug Metabolism Genotyping Assays (Applied Biosystems, Foster City, CA, USA) with the Applied Biosystems 7500 Real-Time PCR System. CYP2C19*2 and *3 are considered to account for more than $99 \%$ of alleles generating the null-activity enzyme protein in the Japanese population. ${ }^{14}$ Thus, CYP2C19 genotypes were classified into 3 phenotypes: (1) extensive metabolizers (EM) carrying normal function al-

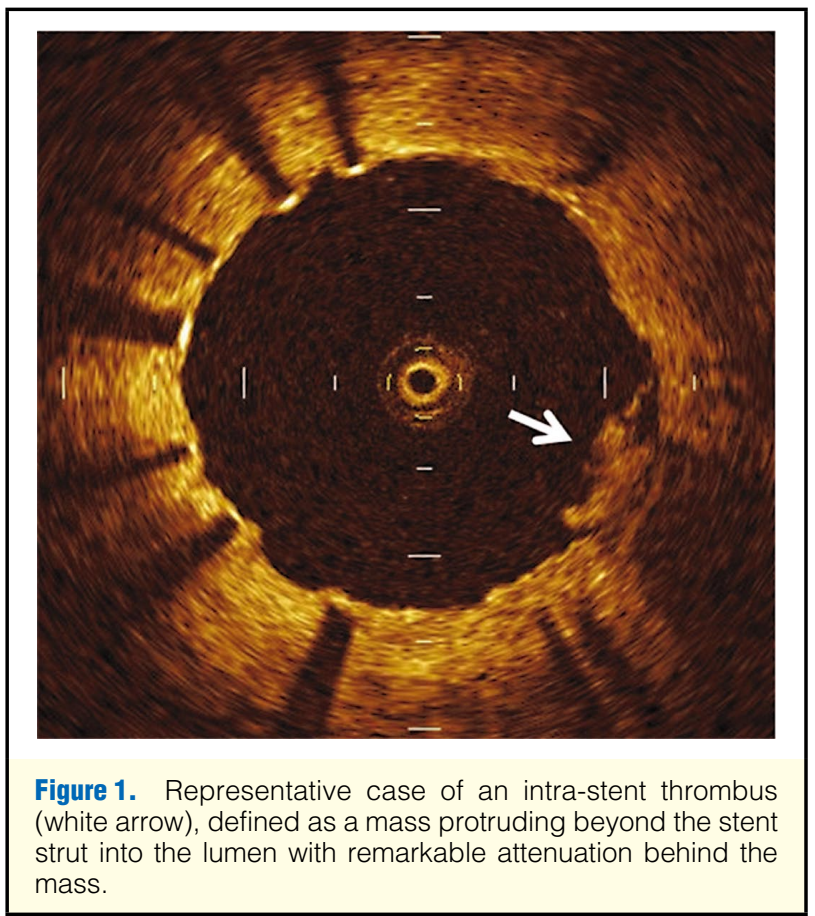

leles (CYP2C19*1/*1); (2) intermediate metabolizers (IM) carrying 1 loss-of-function allele $(* 1 / * 2, * 1 / * 3)$; and (3) poor metabolizers (PM) carrying 2 loss-of-function alleles $(* 2 / * 2$, $* 2 / * 3, * 3 / * 3)$.

\section{Angiographic Analysis}

Cineangiograms were analyzed with a computer-assisted, automated edge detection algorithm (CMS-Medis Medical Imaging Systems, Leiden, The Netherlands). The outer diameter of the contrast-filled catheter was used for calibration and the minimal lumen diameter (MLD) was obtained from the single worst view. Acute gain was defined as the difference between the MLD pre- and post- PCI. In-stent late loss was defined as the difference between the MLD immediately after the procedure and the MLD at the follow-up date. The traditional lesion type was also assessed according to the American Heart Association/American College of Cardiology classification. ${ }^{15}$

\section{OCT Substudy}

OCT Examination To assess the relationship between CYP2C19 polymorphism and local vessel reaction after DES implantation, we performed OCT in some of the enrolled patients at the time of follow-up angiography. Among the overall population of 160 patients, patients with left main trunk disease, ostial disease, and severe 3 -vessel disease $(n=18)$ were excluded from the OCT examination to ensure the safety of the patients during the OCT procedure. Patients with severe tortuous lesions and severely calcified vessels $(n=11)$ were also excluded because of anticipated difficulties in advancing the OCT catheters. In addition, patients with vessels greater than $4.0 \mathrm{~mm}$ in diameter on angiography $(\mathrm{n}=6)$ were excluded, because these vessels were too large for blood flow to be occluded. A total of 125 patients were enrolled in the OCT substudy.

In this study, because frequency-domain OCT was not yet approved for clinical use in Japan, time-domain OCT with coronary artery occlusion was used, as previously reported. ${ }^{16}$ 


\begin{tabular}{|c|c|c|c|c|}
\hline & $\operatorname{EM}(n=60)$ & IM $(n=77)$ & $P M(n=23)$ & $P$ value \\
\hline Age (years) & $69.4 \pm 10.3$ & $69.8 \pm 8.9$ & $70.6 \pm 7.3$ & 0.87 \\
\hline Sex (male; $n)$ & $43(71.7)$ & $62(80.5)$ & $17(73.9)$ & 0.46 \\
\hline Body mass index $\left(\mathrm{kg} / \mathrm{m}^{2}\right)$ & $24.5 \pm 2.8$ & $23.6 \pm 3.6$ & $23.8 \pm 3.6$ & 0.31 \\
\hline Acute coronary syndrome $(n)$ & $6(10.0)$ & $8(10.4)$ & $2(8.7)$ & 0.97 \\
\hline Hypertension (n) & $52(86.7)$ & 60 (77.9) & $20(87.0)$ & 0.34 \\
\hline Dyslipidemia (n) & $40(66.7)$ & $52(67.5)$ & $16(69.6)$ & 0.97 \\
\hline Diabetes $(n)$ & $27(45.0)$ & $39(50.6)$ & $9(39.1)$ & 0.58 \\
\hline Smoker (n) & $21(35.0)$ & $33(42.9)$ & $9(39.1)$ & 0.65 \\
\hline eGFR $\left(\mathrm{ml} \cdot \mathrm{min}^{-1} \cdot 1.73 \mathrm{~m}^{-2}\right)$ & $59.6 \pm 18.9$ & $60.5 \pm 20.9$ & $56.8 \pm 25.0$ & 0.76 \\
\hline \multicolumn{5}{|l|}{ Medications } \\
\hline PPI (n) & $29(48.3)$ & $40(51.9)$ & $10(43.5)$ & 0.76 \\
\hline Omeprazole (n) & $3(5.0)$ & $6(7.8)$ & $2(8.7)$ & 0.75 \\
\hline $\mathrm{CCB}(\mathrm{n})$ & $28(46.7)$ & $36(46.8)$ & $11(47.8)$ & 0.99 \\
\hline Statin $(n)$ & $43(71.7)$ & $54(70.1)$ & $16(69.6)$ & 0.89 \\
\hline$\beta$-blocker (n) & $25(41.7)$ & 39 (50.6) & $10(43.4)$ & 0.55 \\
\hline ACEI or ARB (n) & $45(75.0)$ & $57(74.0)$ & $18(78.3)$ & 0.92 \\
\hline Warfarin (n) & $3(5.0)$ & $4(5.2)$ & $1(4.3)$ & 0.99 \\
\hline
\end{tabular}

Data are presented as mean \pm SD or $n(\%)$.

EM, extensive metabolizer; IM, intermediate metabolizer; PM, poor metabolizer; ACEI, angiotensin-converting enzyme inhibitor; ARB, angiotensin-receptor blocker; CCB, calcium-channel blocker; eGFR, estimated glomerular filtration rate; PPI, proton-pump inhibitor.

Briefly, a 0.016-inch OCT wire (ImageWire, LightLab Imaging, Westford, MA, USA) was advanced to the distal end of the stented lesion through an occlusion balloon catheter (HeliosTM, LightLab Imaging). The occlusion balloon was inflated to $0.5 \mathrm{~atm}$ at the proximal site of the stented lesion, followed by an infusion of lactated Ringer's solution into the coronary artery from the distal tip of the occlusion balloon catheter at $0.5 \mathrm{ml} / \mathrm{s}$, serving as a flush to clear the area of blood. The entire stented length was then imaged using an automatic pullback system moving at $1 \mathrm{~mm} / \mathrm{s}$.

OCT Analysis Cross-sectional images were analyzed at 1$\mathrm{mm}$ (15 frames) intervals. Bifurcation lesions with major side branches were excluded from the study. All images were analyzed by 2 independent observers blinded to the clinical presentation and lesion characteristics. Neointimal thickness inside each stent strut was measured on each cross-section. Stent diameters (maximum and minimum) and area were also measured manually. A stent strut with a measured thickness of $0 \mu \mathrm{m}$ was defined as an uncovered strut and a maximum distance of more than $170 \mu \mathrm{m}$ between the center reflection of the strut and adjacent vessel surface was defined as stent malapposition. This criterion was determined by adding the actual strut thickness and polymer thickness to the OCT resolution limit $(140 \mu \mathrm{m}+10 \mu \mathrm{m}+20 \mu \mathrm{m}$ for the SES; $130 \mu \mathrm{m}+14 \mu \mathrm{m}+$ $20 \mu \mathrm{m}$ for the PES). ${ }^{17,18}$ The numbers of uncovered struts and malapposed struts were calculated and described as the frequency (number of malapposed struts divided by total number of struts). A stent eccentricity index and a neointimal unevenness score were calculated, because these parameters are reported to be predictive factors for intra-SES thrombus. ${ }^{19}$ The stent eccentricity index was calculated as the minimum stent diameter divided by the maximum stent diameter in each cross-section. The neointimal unevenness score was calculated as the maximum neointimal thickness in 1 cross-section divided by the mean neointimal thickness of the same crosssection. Intra-stent thrombus was defined as a mass protruding beyond the stent strut into the lumen with significant attenua- tion behind the mass. ${ }^{20} \mathrm{~A}$ representative case of an intra-stent thrombus is shown in Figure 1. To quantify the intra-stent thrombi, the maximum area of intra-stent thrombi was measured and the prevalence of intra-stent thrombi was calculated as percentage of cross-sections with intra-stent thrombi (number of cross-sections with intra-stent thrombi $\times 100 /$ total crosssections for the stent).

\section{Clinical Follow-up}

In the present study, clinical follow-up data (up to 3 years after the index procedure) were obtained from outpatient record reviews or telephone interviews. Death, cardiac death, myocardial infarction (MI, defined according to the WHO definition based on creatine kinase and creatine kinase-MB rise), ${ }^{21}$ clinically-driven target lesion revascularization (TLR, defined as repeat PCI or coronary artery bypass graft to the target lesion), stent thrombosis (adjudicated according to the Academic Research Consortium classification), ${ }^{22}$ and the composite endpoints of major adverse cardiac events (MACE: cardiac death, MI, TLR, stent thrombosis) were evaluated during the followup period.

\section{Statistical Analysis}

All statistical analyses were performed using Medcalc (version 12.1; Medcalc Software, Mariakerke, Belgium). Continuous variables are presented as the mean $\pm \mathrm{SD}$. Differences in continuous parameters between the 3 groups were calculated using a 1-way ANOVA. Categorical variables are presented as frequency counts. Comparison of categorical variables between the 3 groups was performed using the chi-square test. Values were considered statistically significant at $\mathrm{P}<0.05$. Cumulative incidences were analyzed from time of DES implantation to the first event according to the Kaplan-Meier method, and the differences were calculated by the log-rank test. 


\begin{tabular}{|c|c|c|c|c|}
\hline & $\operatorname{EM}(n=60)$ & IM $(n=77)$ & $P M(n=23)$ & $P$ value \\
\hline \multicolumn{5}{|l|}{ Lesion location } \\
\hline LAD (n) & 27 & 40 & 11 & \\
\hline $\operatorname{LCX}(n)$ & 15 & 18 & 8 & \\
\hline $\mathrm{RCA}(\mathrm{n})$ & 25 & 24 & 6 & 0.61 \\
\hline \multicolumn{5}{|l|}{ Type of lesion } \\
\hline $\mathrm{A} / \mathrm{B} 1(\mathrm{n})$ & 32 & 42 & 10 & \\
\hline $\mathrm{B} 2 / \mathrm{C}(\mathrm{n})$ & 28 & 35 & 13 & 0.64 \\
\hline CTO (n) & $11(18.3)$ & $17(22.1)$ & $5(21.7)$ & 0.84 \\
\hline Bifurcation lesion (n) & $18(30.0)$ & $29(37.7)$ & $8(34.8)$ & 0.61 \\
\hline \multicolumn{5}{|l|}{ Procedural characteristics } \\
\hline Total no. of stents $(n)$ & $1.92 \pm 1.06$ & $1.74 \pm 0.77$ & $1.65 \pm 0.89$ & 0.38 \\
\hline SES (n) & $1.13 \pm 1.05$ & $1.12 \pm 0.87$ & $1.17 \pm 0.78$ & 0.97 \\
\hline PES (n) & $0.80 \pm 0.92$ & $0.62 \pm 0.84$ & $0.48 \pm 0.59$ & 0.29 \\
\hline Total stent length (mm) & $36.6 \pm 22.8$ & $38.0 \pm 23.3$ & $29.8 \pm 14.7$ & 0.29 \\
\hline Stent diameter $(\mathrm{mm})$ & $2.89 \pm 0.39$ & $2.81 \pm 0.36$ & $2.75 \pm 0.33$ & 0.26 \\
\hline Post dilatation (n) & $31(51.7)$ & $44(57.1)$ & $10(43.5)$ & 0.37 \\
\hline Max. inflation pressure (atm) & $14.7 \pm 3.7$ & $13.6 \pm 4.3$ & $15.0 \pm 2.8$ & 0.23 \\
\hline Overlap stent $(n)$ & $17(28.3)$ & $16(26.2)$ & $3(13.0)$ & 0.28 \\
\hline Rotablation (n) & $1(1.7)$ & $8(10.4)$ & $1(4.3)$ & 0.08 \\
\hline \multicolumn{5}{|c|}{ Quantitative coronary angiography } \\
\hline Lesion length (mm) & $9.2 \pm 4.5$ & $9.1 \pm 5.0$ & $10.4 \pm 5.9$ & 0.56 \\
\hline Reference diameter (mm) & $2.22 \pm 0.51$ & $2.18 \pm 0.70$ & $2.06 \pm 0.44$ & 0.59 \\
\hline \multicolumn{5}{|l|}{ Minimum lumen diameter } \\
\hline Before PCl $(\mathrm{mm})$ & $0.37 \pm 0.30$ & $0.37 \pm 0.34$ & $0.37 \pm 0.25$ & 0.99 \\
\hline After PCl (mm) & $2.36 \pm 0.43$ & $2.25 \pm 0.44$ & $2.21 \pm 0.36$ & 0.21 \\
\hline Follow-up (mm) & $1.96 \pm 0.55$ & $1.79 \pm 0.61$ & $1.82 \pm 0.48$ & 0.22 \\
\hline \multicolumn{5}{|l|}{$\%$ diameter stenosis } \\
\hline Before $\mathrm{PCl}(\%)$ & $80.9 \pm 14.2$ & $78.0 \pm 16.7$ & $83.4 \pm 13.8$ & 0.28 \\
\hline After PCl (\%) & $11.9 \pm 5.2$ & $12.8 \pm 6.5$ & $13.0 \pm 6.4$ & 0.69 \\
\hline Follow-up (\%) & $22.9 \pm 16.0$ & $25.2 \pm 19.4$ & $24.4 \pm 16.8$ & 0.78 \\
\hline Acute gain $(\mathrm{mm})$ & $1.92 \pm 0.47$ & $1.85 \pm 0.48$ & $1.78 \pm 0.54$ & 0.42 \\
\hline Late loss (mm) & $0.46 \pm 0.34$ & $0.52 \pm 0.48$ & $0.43 \pm 0.36$ & 0.54 \\
\hline
\end{tabular}

Data are presented as mean \pm SD or $n(\%)$

$\mathrm{PCl}$, percutaneous coronary intervention; LAD, left anterior descending artery; LCX, left circumflex artery; RCA, right coronary artery; CTO, chronic total occlusion; SES, sirolimus-eluting stent; PES, paclitaxel-eluting stent. Other abbreviations as in Table 1.

\begin{tabular}{|lcccc|}
\hline Table 3. MACE & & & & \\
& EM $(\mathbf{n}=\mathbf{6 0})$ & IM $(\mathbf{n}=\mathbf{7 7})$ & PM $(\mathbf{n}=\mathbf{2 3})$ & P value \\
Death $(n)$ & $1(1.7)$ & $2(2.6)$ & $2(8.7)$ & 0.24 \\
Cardiac death $(n)$ & 0 & $2(2.6)$ & 0 & 0.34 \\
Myocardial infarction $(n)$ & $1(1.7)$ & $1(1.3)$ & $1(4.3)$ & 0.69 \\
TLR $(n)$ & $2(3.3)$ & $14(18.2)^{\star}$ & $6(26.1)^{\star *}$ & 0.008 \\
Stent thrombosis $(n)$ & $1(1.7)$ & $2(2.6)$ & $1(4.3)$ & 0.79 \\
MACE $(n)$ & $3(5.0)$ & $17(22.1)^{\dagger}$ & $7(30.4)^{\ddagger}$ & 0.005 \\
\hline
\end{tabular}

Data are presented as $n(\%) .{ }^{*} \mathrm{P}=0.04,{ }^{* \star} \mathrm{P}=0.02,{ }^{\mathrm{P}} \mathrm{P}=0.03,{ }^{\ddagger} \mathrm{P}=0.02$ (compared with $\mathrm{EM}$, using Scheffe's post hoc test). MACE, major adverse cardiac events; TLR, target lesion revascularization. Other abbreviations as in Table 1.

\section{Results}

Of the 160 patients who were enrolled in this study, the proportions of EM, IM, and PM were $37.5 \%, 48.1 \%$, and $14.4 \%$, respectively $(* 1 / * 1,37.5 \% ; * 1 / * 2,30.6 \% ; * 1 / * 3,17.5 \%$; $* 2 / * 2,5.6 \% ; * 2 / * 3,6.3 \% ; * 3 / * 3,2.5 \%)$. Mean age was $69.7 \pm 9.2$ years and mean follow-up duration was $646.2 \pm 255.2$ days (median, 692.5 days). The mean duration of clopidogrel treatment was 475.9 \pm 206.1 days in EM, 465.5 \pm 223.9 days in IM, and $454.9 \pm 213.3$ days in PM, and was not statistically different among groups $(\mathrm{P}=0.92)$.

The baseline characteristics of the study population are listed in Table 1. Patient characteristics did not differ significantly among the 3 groups. There were no differences in the use of omeprazole or calcium-channel blocker among the groups. The lesion and procedural characteristics are shown in Table 2. 


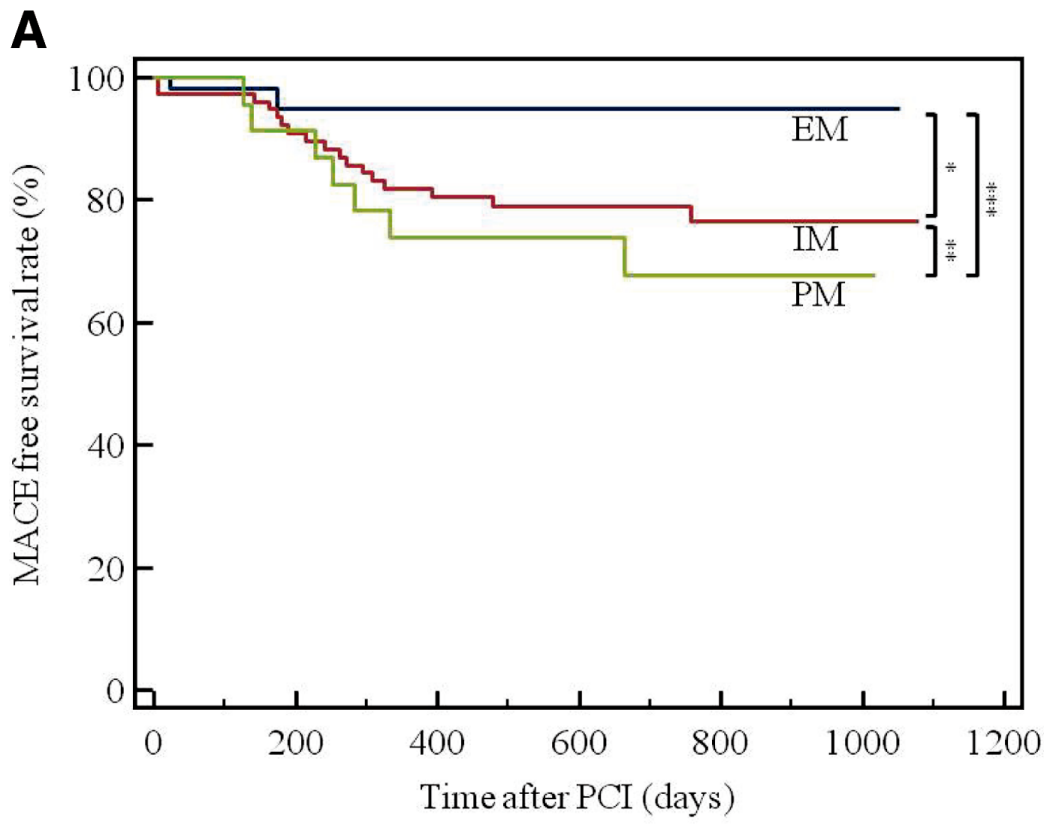

B

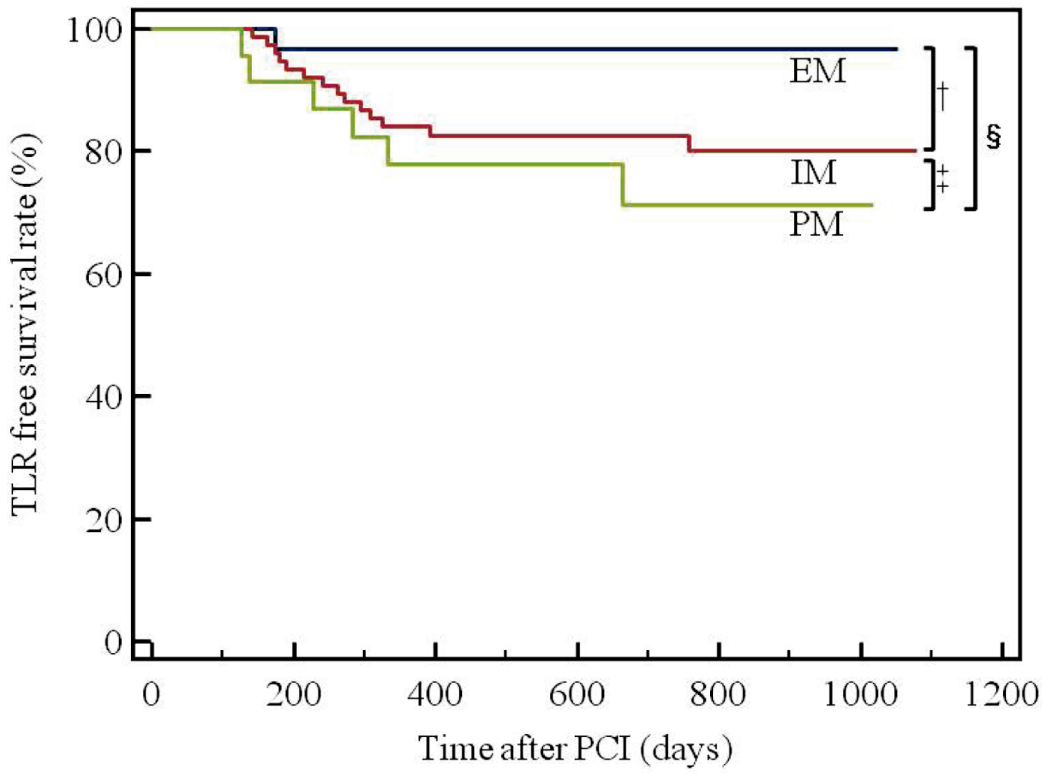

Figure 2. MACE-free survival curve and TLR-free survival curve. EM, extensive metabolizer; IM, intermediate metabolizer; PM, poor metabolizer; MACE, major adverse cardiac event; TLR, target lesion revascularization; $\mathrm{PCl}$, percutaneous coronary intervention. ${ }^{*} \mathrm{P}=0.007,{ }^{* *} \mathrm{P}=0.44$, ${ }^{* * *} \mathrm{P}=0.002,{ }^{\dagger} \mathrm{P}=0.009$, $\neq \mathrm{P}=0.42, \S \mathrm{P}=0.002$.

No difference in the quantitative coronary angiography data or procedural characteristics was noted among the 3 groups.

The incidences of MACE and TLR were significantly higher in IM and PM than in EM (Table 3). The incidences of death, MI, and stent thrombosis did not differ among the 3 groups. The Kaplan-Meier cumulative MACE- and TLR-free survival curves with a log-rank test showed that the presence of CYP2C19 loss-of-function polymorphisms was associated with higher incidences of MACE and TLR after PCI, which were sustained for at least 3 years after DES implantation (Figures 2A,2B).

Of the 125 patients enrolled in the OCT subgroup analysis, 5 were excluded because of poor image acquisition. Therefore, the OCT data for 120 patients were analyzed. Baseline and procedural characteristics did not differ among the 3 metabolizer groups. The mean follow-up duration was $231.5 \pm 75.4$ days (median, 225.0 days). The percentages of EM, IM, and PM were $36.7 \%, 47.5 \%$, and $15.8 \%$, respectively. Qualitative OCT analysis revealed that intra-stent thrombi were more frequently observed in IM and PM than in EM (Figure 3). There were no other differences in the quantitative and qualitative OCT analyses among the 3 groups. The maximum area and \% cross-sections with intra-stent thrombi were not different among the 3 groups (Table 4). The incidence of TLR was significantly higher in patients with intra-stent thrombi than in those without intra-stent thrombi (Figure 4). 


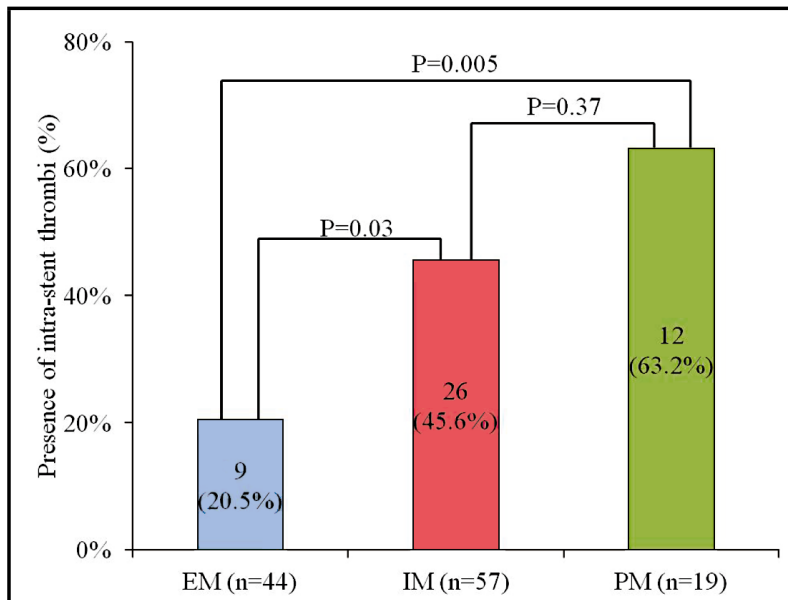

Figure 3. Presence of intra-stent thrombi. Data are presented as $\mathrm{n}(\%)$. EM, extensive metabolizer; IM, intermediate metabolizer; PM, poor metabolizer.

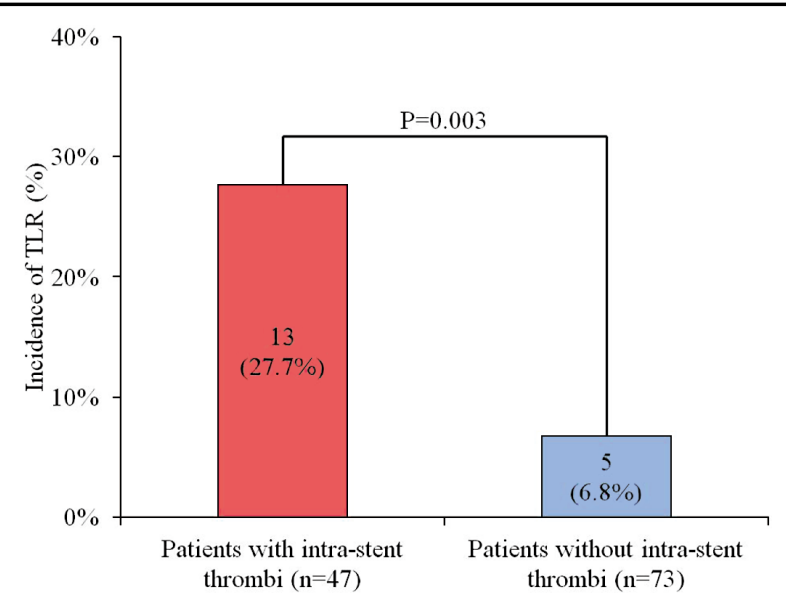

Figure 4. Incidence of TLR in patients with and without intrastent thrombi. Data are presented as n (\%). TLR, target lesion revascularization.

\begin{tabular}{|c|c|c|c|c|}
\hline & $\operatorname{EM}(n=44)$ & IM $(n=57)$ & PM (n=19) & $P$ value \\
\hline Number of struts (n) & $160.1 \pm 81.9$ & $193.2 \pm 83.7$ & $179.7 \pm 75.8$ & 0.15 \\
\hline Frequency of malapposed struts (\%) & $1.7 \pm 1.9$ & $2.0 \pm 2.0$ & $1.9 \pm 2.0$ & 0.79 \\
\hline Number of malapposed struts (n) & $3.2 \pm 4.0$ & $4.1 \pm 3.9$ & $3.3 \pm 3.7$ & 0.54 \\
\hline Frequency of uncovered struts (\%) & $7.4 \pm 7.1$ & $6.8 \pm 6.7$ & $7.4 \pm 6.3$ & 0.90 \\
\hline Number of uncovered struts ( $n$ ) & $12.6 \pm 13.2$ & $12.2 \pm 12.5$ & $12.5 \pm 13.4$ & 0.99 \\
\hline Minimum stent diameter (mm) & $2.89 \pm 0.40$ & $2.73 \pm 0.42$ & $2.80 \pm 0.39$ & 0.15 \\
\hline Stent eccentricity index & $0.92 \pm 0.04$ & $0.93 \pm 0.04$ & $0.92 \pm 0.05$ & 0.94 \\
\hline Mean neointimal thickness $(\mathrm{mm})$ & $0.12 \pm 0.08$ & $0.11 \pm 0.07$ & $0.13 \pm 0.13$ & 0.86 \\
\hline Neointimal unevenness score & $1.94 \pm 0.33$ & $1.90 \pm 0.31$ & $1.89 \pm 0.17$ & 0.71 \\
\hline Mean stent area $\left(\mathrm{mm}^{2}\right)$ & $7.42 \pm 1.96$ & $6.74 \pm 1.87$ & $7.02 \pm 1.84$ & 0.22 \\
\hline Minimum stent area $\left(\mathrm{mm}^{2}\right)$ & $5.81 \pm 1.82$ & $5.56 \pm 1.63$ & $5.53 \pm 1.68$ & 0.74 \\
\hline $\begin{array}{l}\text { Maximum area of intra-stent thrombi } \\
\left(\mathrm{mm}^{2}\right)^{\star}\end{array}$ & $0.29 \pm 0.22$ & $0.61 \pm 1.01$ & $0.89 \pm 1.53$ & 0.47 \\
\hline $\begin{array}{l}\% \text { cross-sections with intra-stent thrombi } \\
(\%)^{\star}\end{array}$ & $4.88 \pm 3.00$ & $6.61 \pm 14.36$ & $9.87 \pm 19.64$ & 0.72 \\
\hline
\end{tabular}

Data are presented as mean \pm SD.

OCT, optical coherence tomography. Other abbreviations as in Table 1.

${ }^{*}$ Maximum area and \% cross-sections with intra-stent thrombi were calculated only in the patients with intra-stent thrombi.

\section{Discussion}

In this study, the proportions of EM, IM, and PM were $37.5 \%$, $48.1 \%$, and $14.4 \%$, respectively. During the median follow-up of 692.5 days, the incidence of MACE and TLR was significantly higher in IM and PM than in EM. In a subgroup analysis of 120 patients who underwent follow-up OCT (median, 225.0 days), intra-stent thrombi were more frequently observed in IM and PM than in EM, although there were no significant differences in other quantitative or qualitative OCT parameters. In this OCT subgroup population, the incidence of TLR was significantly higher in patients with intra-stent thrombi than in those without intra-stent thrombi.

Previous studies have consistently reported a relatively high incidence of CYP2C19 loss-of-function carriers in Asian populations. The frequency of CYP2C19*2 is higher in Asians (30-50\%) than in Western people (20-30\%), and the CYP2C19*3 allele is frequent in Asians (10-20\%) and rare in Caucasians (approximately $0.5 \%)^{3,23-26}$ In the present study, the proportions of EM, IM, and PM were $37.5 \%, 48.1 \%$, and $14.4 \%$, respectively, which is consistent with previous studies in Japanese populations. ${ }^{27-29}$ Because the population of CYP2C19 loss-offunction carriers is not small, not only in the Japanese but also in the Western population, clarifying the effect of CYP2C19 loss-of-function on future clinical events is vital.

In this study, patients with CYP2C19 loss-of-function polymorphisms had a higher incidence of TLR and MACE compared with patients without the polymorphisms. Several studies of DES restenosis and pathologic examinations of human specimens have demonstrated that neointimal tissues after DES implantation comprises heterogeneous components, including proteoglycan-rich tissue, organized thrombus, smooth muscle cells, atheroma, inflammatory cells, and fibrinoid. ${ }^{30}$ Among these components, previous investigators implied that thrombus formation has an important role in the process of DES restenosis. A pathologic analysis of recent human SES 
restenosis demonstrated the presence of fibrin deposition and a myxomatous extracellular matrix within restenotic tissue..$^{10}$ Also, based on their analysis of restenotic tissue collected through directional coronary atherectomy, Oikawa et al reported that the tissues comprising human SES restenosis are frequently associated with thrombus components. ${ }^{11}$ Similarly, in the present study, the incidence of TLR was higher in patients with intra-stent thrombi than in those without intra-stent thrombi and the incidence of intra-stent thrombi increased with an increase in the number of CYP2C19 polymorphisms. Therefore, we speculate that the presence of CYP2C19 loss-of-function polymorphisms might increase the possibility for TLR because of an increased incidence of DES restenosis through insufficient suppression of thrombus formation by clopidogrel. Interestingly, the difference in the incidence of TLR and MACE occurred mostly in the early phase, mainly up to 1 year after the index PCI. Oh et $\mathrm{al}^{7}$ reported that the CYP2C19*2 allele carrier status was associated with an increased incidence of adverse clinical events, including stent thrombosis up to 1 year after stenting. Such association, however, no longer existed after 1 year, at which time most of the patients in their study population had discontinued clopidogrel, ${ }^{7}$ which was similar to our present study population, in which most of the patients (66.9\%) discontinued clopidogrel intake 1 year after stenting. These results support our speculation.

Although previous studies have described a highly significant association of CYP2C19 loss-of-function polymorphisms and stent thrombosis, ${ }^{3,6,31,32}$ in our study population the incidence of stent thrombosis was not significantly different among the 3 metabolizer groups. We speculate that this is mainly related to the small sample size of our study and the relatively short duration of the follow-up period under clopidogrel treatment. On the other hand, we demonstrated a possible association between CYP2C19 loss-of-function polymorphisms and TLR, although most previous studies failed to show such a finding. ${ }^{9}$ Although still speculative, we currently consider that mandatory mid-term angiographic follow-up with detailed OCT assessment performed for more than $75 \%$ of enrolled patients might help detect such tiny differences observed in the present study. Although the rationale for mid-term follow-up angiography is controversial, this practice might help to detect severe luminal narrowing before the development of late stent thrombosis.

\section{Study Limitations}

Because only the patients who revisited hospital for followup angiography were enrolled in this study, some selection bias is likely. Also, because of the observational study design based on a limited sample size, it remains unclear whether the CYP2C19 loss-of-function polymorphisms increase the incidence of stent thrombosis. Further, this study only examined SES and PES and there was no comparison with bare metal stents and other DES. Residual platelet reactivity was not evaluated in this study. The relationship between the incidence of intra-stent thrombi and residual platelet reactivity is unclear and further study is warranted.

\section{Conclusions}

Our results suggest that CYP2C19 loss-of-function polymorphisms are associated with an increased incidence of MACE, especially because of the increased incidence in early-phase TLR (within 1 year) after DES implantation in Japanese patients receiving clopidogrel.

\section{References}

1. King SB 3rd, Smith SC Jr, Hirshfeld JW Jr, Jacobs AK, Morrison DA, Williams DO, et al. 2007 Focused Update of the ACC/AHA/ SCAI 2005 Guideline Update for Percutaneous Coronary Intervention: A report of the American College of Cardiology/American Heart Association Task Force on Practice Guidelines: 2007 Writing Group to Review New Evidence and Update the ACC/AHA/SCAI 2005 Guideline Update for Percutaneous Coronary Intervention, Writing on Behalf of the 2005 Writing Committee. Circulation 2008; 117: $261-295$

2. Kubica A, Kozinski M, Grzesk G, Fabiszak T, Navarese EP, Goch A. Genetic determinants of platelet response to clopidogrel. J Thromb Thrombolysis 2011; 32: 459-466.

3. Mega JL, Close SL, Wiviott SD, Shen L, Hockett RD, Brandt JT, et al. Cytochrome P-450 polymorphisms and response to clopidogrel. $N$ Engl J Med 2009; 360: 354-362.

4. Pettersen AA, Arnesen H, Opstad TB, Seljeflot I. The influence of CYP 2C19*2 polymorphism on platelet function testing during single antiplatelet treatment with clopidogrel. Thromb J 2011; 9: 4.

5. Sibbing D, Koch W, Gebhard D, Schuster T, Braun S, Stegherr J, et al. Cytochrome 2C19*17 allelic variant, platelet aggregation, bleeding events, and stent thrombosis in clopidogrel-treated patients with coronary stent placement. Circulation 2010; 121: 512-518.

6. Sibbing D, Stegherr J, Latz W, Koch W, Mehilli J, Dorrler K, et al. Cytochrome P450 2C19 loss-of-function polymorphism and stent thrombosis following percutaneous coronary intervention. Eur Heart J 2009; 30: 916-922.

7. Oh IY, Park KW, Kang SH, Park JJ, Na SH, Kang HJ, et al. Association of cytochrome $\mathrm{P} 4502 \mathrm{C} 19 * 2$ polymorphism with clopidogrel response variability and cardiovascular events in Koreans treated with drug-eluting stents. Heart 2012; 98: 139-144.

8. Zabalza M, Subirana I, Sala J, Lluis-Ganella C, Lucas G, Tomas M, et al. Meta-analyses of the association between cytochrome CYP2C19 loss- and gain-of-function polymorphisms and cardiovascular outcomes in patients with coronary artery disease treated with clopidogrel. Heart 2012; 98: 100-108.

9. Sawada T, Shinke T, Shite J, Honjo T, Haraguchi Y, Nishio R, et al. Impact of cytochrome $\mathrm{P} 4502 \mathrm{C} 19 * 2$ polymorphism on intra-stent thrombus after drug-eluting stent implantation in Japanese patients receiving clopidogrel. Circ J 2010; 75: 99-105.

10. Nagai H, Ishibashi-Ueda H, Fujii K. Histology of highly echolucent regions in optical coherence tomography images from two patients with sirolimus-eluting stent restenosis. Catheter Cardiovasc Interv 2010; 75: $961-963$.

11. Oikawa Y, Yajima J, Costa MA, Matsuno S, Akabane M, Funada R, et al. Intravascular ultrasound, angioscopic and histopathological characterisation of heterogeneous patterns of restenosis after sirolimuseluting stent implantation: Insights into potential "thromborestenosis" phenomenon. EuroIntervention 2010; 6: 380-387.

12. Furuta T, Iwaki T, Umemura K. Influences of different proton pump inhibitors on the anti-platelet function of clopidogrel in relation to CYP2C19 genotypes. Br J Clin Pharmacol 2010; 70: 383-392.

13. Gremmel T, Steiner S, Seidinger D, Koppensteiner R, Panzer S, Kopp CW. Calcium-channel blockers decrease clopidogrel-mediated platelet inhibition. Heart 2010; 96: 186-189.

14. Kubota T, Chiba K, Ishizaki T. Genotyping of S-mephenytoin 4'hydroxylation in an extended Japanese population. Clin Pharmacol Ther 1996; 60: 661-666.

15. Ryan TJ, Faxon DP, Gunnar RM, Kennedy JW, King SB 3rd, Loop $\mathrm{FD}$, et al. Guidelines for percutaneous transluminal coronary angioplasty: A report of the American College of Cardiology/American Heart Association Task Force on Assessment of Diagnostic and Therapeutic Cardiovascular Procedures (Subcommittee on Percutaneous Transluminal Coronary Angioplasty). Circulation 1988; 78: 486502 .

16. Matsumoto D, Shite J, Shinke T, Otake H, Tanino Y, Ogasawara D, et al. Neointimal coverage of sirolimus-eluting stents at 6-month follow-up: Evaluated by optical coherence tomography. Eur Heart J 2007; 28: $961-967$.

17. Sawada T, Shite J, Negi N, Shinke T, Tanino Y, Ogasawara D, et al. Factors that influence measurements and accurate evaluation of stent apposition by optical coherence tomography: Assessment using a phantom model. Circ J 2009; 73: 1841-1847.

18. Miyoshi N, Shite J, Shinke T, Otake H, Tanino Y, Ogasawara D, et al. Comparison by optical coherence tomography of paclitaxel-eluting stents with sirolimus-eluting stents implanted in one coronary artery in one procedure: 6-month follow-up. Circ J 2010; 74: $903-$ 908.

19. Otake H, Shite J, Ako J, Shinke T, Tanino Y, Ogasawara D, et al. 
Local determinants of thrombus formation following sirolimus-eluting stent implantation assessed by optical coherence tomography. JACC Cardiovasc Interv 2009; 2: 459-466.

20. Kume T, Akasaka T, Kawamoto T, Ogasawara Y, Watanabe N, Toyota E, et al. Assessment of coronary arterial thrombus by optical coherence tomography. Am J Cardiol 2006; 97: 1713-1717.

21. Nomenclature and criteria for diagnosis of ischemic heart disease. Report of the Joint International Society and Federation of Cardiology/World Health Organization task force on standardization of clinical nomenclature. Circulation 1979; 59: 607-609.

22. Mauri L, Hsieh WH, Massaro JM, Ho KK, D'Agostino R, Cutlip DE. Stent thrombosis in randomized clinical trials of drug-eluting stents. N Engl J Med 2007; 356: 1020-1029.

23. Wallentin L, James S, Storey RF, Armstrong M, Barratt BJ, Horrow $\mathrm{J}$, et al. Effect of CYP2C19 and ABCB1 single nucleotide polymorphisms on outcomes of treatment with ticagrelor versus clopidogrel for acute coronary syndromes: A genetic substudy of the PLATO trial. Lancet 2010; 376: 1320-1328.

24. Harmsze A, van Werkum JW, Bouman HJ, Ruven HJ, Breet NJ, Ten Berg JM, et al. Besides CYP2C19*2, the variant allele CYP2C9*3 is associated with higher on-clopidogrel platelet reactivity in patients on dual antiplatelet therapy undergoing elective coronary stent implantation. Pharmacogenet Genomics 2010; 20: 18-25.

25. Kim KA, Song WK, Kim KR, Park JY. Assessment of CYP2C19 genetic polymorphisms in a Korean population using a simultaneous multiplex pyrosequencing method to simultaneously detect the CYP2C19*2, CYP2C19*3, and CYP2C19*17 alleles. J Clin Pharm Ther 2010; 35: 697-703.
26. Kim IS, Choi BR, Jeong YH, Kwak CH, Kim S. The CYP2C19*2 and CYP2C19*3 polymorphisms are associated with high post-treatment platelet reactivity in Asian patients with acute coronary syndrome. J Thromb Haemost 2009; 7: 897-899.

27. Maeda A, Ando H, Asai T, Ishiguro H, Umemoto N, Ohta M, et al. Differential impacts of CYP2C19 gene polymorphisms on the antiplatelet effects of clopidogrel and ticlopidine. Clin Pharmacol Ther 2011; 89: 229-233.

28. Jinnai T, Horiuchi H, Makiyama T, Tazaki J, Tada T, Akao M, et al. Impact of CYP2C19 polymorphisms on the antiplatelet effect of clopidogrel in an actual clinical setting in Japan. Circ J 2009; 73: $1498-1503$.

29. Umemura K, Furuta T, Kondo K. The common gene variants of CYP2C19 affect pharmacokinetics and pharmacodynamics in an active metabolite of clopidogrel in healthy subjects. J Thromb Haemost 2008; 6: 1439-1441.

30. van Beusekom HM, Saia F, Zindler JD, Lemos PA, Swager-Ten Hoor SL, van Leeuwen MA, et al. Drug-eluting stents show delayed healing: Paclitaxel more pronounced than sirolimus. Eur Heart $J$ 2007; 28: 974-979.

31. Collet JP, Hulot JS, Pena A, Villard E, Esteve JB, Silvain J, et al. Cytochrome $\mathrm{P} 4502 \mathrm{C} 19$ polymorphism in young patients treated with clopidogrel after myocardial infarction: A cohort study. Lancet 2009; 373: 309-317.

32. Giusti B, Gori AM, Marcucci R, Saracini C, Sestini I, Paniccia R, et al. Relation of cytochrome P450 2C19 loss-of-function polymorphism to occurrence of drug-eluting coronary stent thrombosis. Am J Cardiol 2009; 103: 806-811. 